University of Zurich

Department of Economics

Working Paper Series

ISSN 1664-7041 (print)

ISSN 1664-705X (online)

Working Paper No. 173

\title{
Are Subjective Distributions in Inflation Expectations Symmetric?
}

Nikola Mirkov and Andreas Steinhauer

September 2014 


\title{
Are Subjective Distributions in Inflation Expectations Symmetric?*
}

\author{
Nikola Mirkov ${ }^{\dagger}$ \\ Swiss National Bank
}

\author{
Andreas Steinhauer ${ }^{\ddagger}$ \\ University of Zurich
}

August 2014

\begin{abstract}
We conducted an anonymous survey in December 2013 asking around 200 economists worldwide to provide an interval ( $a$ to $b$ ) of average inflation in the US expected "over the next two years". The respondents were also instructed to give a probability of inflation being higher or lower than the mid-interval $(a+b) / 2$. The aggregate distribution of inflation expectations we obtain closely resembles the outcome of the Survey of Professional Forecasters for 1Q2014. More importantly, we find that the subjective probability mass on either side of the mid-interval is not statistically different from 0.5 , which means that the subjective distributions are symmetric. Our results align well with several papers evaluating the Survey of Professional Forecasters or similar data sets and finding no significant departures from symmetry.
\end{abstract}

Keywords: inflation expectations, subjective probability distributions JEL Classifications: C42, E31

*A great thanks to the survey's participants, Rina Rosenblatt-Wisch, Katrin Assenmacher, Rolf Scheufele, John Cochrane, Paul Söderlind, Christian Hepenstrick and seminar participants at the Swiss National Bank. Views expressed in this paper belong to the authors, and do not necessarily reflect the views of the Swiss National Bank.

${ }^{\dagger}$ Nikola Nikodijevic Mirkov, Swiss National Bank, Borsenstrasse 15, 8001 Zurich, Switzerland, E-mail: nikola.mirkov@snb.ch, Tel: +41 795127892

${ }^{\ddagger}$ Andreas Steinhauer, University of Zurich Department of Economics, Schoenberggasse 1, 8001 Zurich, Switzerland, E-mail: andreas.steinhauer@econ.uzh.ch, Tel: +41 446343725 


\section{Introduction}

Inflation expectations constitute a vital part of decision making by companies and policymakers alike. In surveys regarding future inflation, respondents are asked to provide their inflation expectations by specifying a point forecast, an interval ${ }^{1}$ or an entire distribution of possible outcomes ${ }^{2}$. The question of how to aggregate point forecast or interval data and compute summary statistics touches upon a rich literature examining subjective probability distributions. Specifically, if the survey participants had symmetrically distributed inflation expectations within the bounds they provide, the mean of the interval mid-points would be an accurate statistic for average expected inflation, while the average interval width would be one possible measure for the degree of uncertainty associated with this expected mean. When one departs from the assumption of a symmetric distribution, however, it gets more complicated. As García and Manzanares (2007) show in the context of the Survey of Professional Forecasters (SPF), subjective expectation distributions can exhibit skewness, implying that routinely reported summary statistics do not give a good picture of perceived inflation risks. In particular, they document that during the Volcker era, when inflation was low or negative, the SPF respondents' expectations factored in inflation risks, even while mean expected inflation was low or declining. Asymmetries in inflation expectations are important, they argue, as they might explain the inflation scares observed in the bond market (particularly in 1983-1984).

In this paper we conduct a simple survey to directly test for asymmetries in inflation expectations provided in interval form. We make use of the transition of Fed leadership from Ben Bernanke to Janet Yellen in the beginning of 2014 to hide the technical aspect of the survey behind a political framing. In a first step, we ask respondents, a sample of non-professional forecasters with an economic background (so that we can be sure they know what inflation is), to provide intervals for their inflation expectations under Ben Bernanke's or Janet Yellen's leadership. In a second step, we randomize participants into groups which are then asked about the probability they assign to inflation being higher or lower than the midpoints of the intervals they provided. We find that the probabilities provided by

\footnotetext{
${ }^{1}$ For example, the Regional Network Company Survey conducted by the Swiss National Bank (SNB). Survey results are regularly published in the monetary policy report: link (in German).

${ }^{2}$ Most notably, the Survey of Professional Forecasters conducted by the Federal Reserve Bank of Philadelphia: link.
} 
our respondents do not depart significantly from 50\%, using several different statistical techniques. Additionally, we find no evidence for excess perceived inflation risks, as neither the probability that inflation is higher or lower than the midpoint exceed $50 \%$. We also analyze whether inflation expectations are different under Ben Bernanke's or Janet Yellen's leadership. Surprisingly (to us, at least), the average mid-range inflation expectations when only including those that give different intervals for the two scenarios indicate that expected inflation would be higher if Bernanke were to remain the Fed chair. Finally, we conduct robustness checks to mitigate concerns that our results are driven by the non-professionality (in terms of forecasting) of our sample. We do not find that more sophisticated or experienced forecasters' expectations distributions exhibit a different degree of asymmetry.

Our paper relates to the literature on the analysis of expectation surveys, such as the Survey of Professional Forecasters (SPF). There is no consensus yet on the correct distribution to model subjective expectations. García and Manzanares (2007) find skewness at certain points in time, which is also what Lahiri, Teigland and Zaporowski (1988) find, using a different data set. Murasawa (2013) reports similar findings for household inflation expectations. Contrary to these findings, Clements (2014) finds little evidence for asymmetry in SPF inflation expectation distributions. In line with the latter paper and using survey data, De Bruin, Manski, Topa and van der Klaauw (2011) find that the mean of individual distributions is an accurate statistic for expected inflation at the aggregate level, but, on the other hand, in many cases poorly describes individual expectations. A different but related strand of the literature compares forecasters' point predictions with the central tendencies of their subjective probability distributions, generally finding that the two measures do not always agree (Engelberg, Manski and Williams (2009), Clements (2010)).

Our paper provides guidance for the design and analysis of expectation surveys in general and inflation expectation surveys in particular. We contribute to the literature on subjective expectations with our finding that the inflation expectation distributions of our sample of non-professional forecasters with an economic background do not exhibit asymmetry, using a unique experimental set-up. Our paper is structured as follows. Section 2 describes the survey, section 3 illustrates the extracted inflation expectations, section 4 analyzes the provided subjective distributions and describes several robustness checks we performed. 


\section{The Survey}

In this section we detail our survey methodology. We designed the survey to be short in order to get a maximum response rate. Respondents answered 4 questions regarding headline inflation expectations in the U.S. over the next two years. The target audience were non-professional forecasters with an economic background, so that we could be sure that they were familiar with the basic concepts and knew who Ben Bernanke and Janet Yellen are. We sent invitations to complete the online survey by email between December 2013 and February 2014, providing a link to a homepage hosted by the University of Zurich. The survey was answered by about 200 economists from the Federal Reserve System, European System of Central Banks, Norges Bank, Riksbank, Stanford University, University of Chicago, Columbia University, University of California at Berkeley, Bocconi University, University of St. Gallen, University of Zurich and Swiss National Bank, among others. The online survey presented participants with four questions on three pages and saved their answers in a database. The estimated response time was roughly 1.5 minutes.

An overview of the four questions is given in Table 1. The first question, "Do you have a background in economics and/or statistics?" (yes/no), was designed to test whether we reached the target audience and used to select only those that actually did have such a background. In question 2 , respondents were asked to provide an interval for their expectation regarding headline inflation in the next two years after Janet Yellen begins her appointment as chair of the Federal Reserve. In question 3, respondents were asked to provide an interval under the counterfactual assumption that Ben Bernanke would remain at that post. For question 4 we randomly assigned participants into one of four groups as detailed in Table 1 . We asked participants to report the probability (in \%) that average headline inflation would be below (groups 1 and 3) or above (groups 2 and 4) the mid-point of the interval that they provided in questions 2 and 4, if Ben Bernanke had remained chairman (groups 1 and 2) or under Janet Yellen (groups 3 and 4).

The political framing of the questions was intended to prevent participants from answering the survey as if it was a purely technical inquiry. We anticipated that most of the respondents in our sample would be well aware of different methods to estimate inflation, and we intended to put the focus on a real world scenario instead of pure technicalities. Questions 2 and 3 were posed on the same survey page 
so that respondents directly saw that they needed to provide two intervals, one for Janet Yellen as chair, and one for Ben Bernanke as chair. The intention, beside distracting respondents from technicalities, was to see whether political beliefs cause shifts in the probability distributions. The randomization regarding whether average inflation would be below or above the mid-point of the respondent-provided interval intended to capture asymmetries in the distribution. 


\section{Table 1: Survey Design}

\begin{tabular}{|c|c|c|c|}
\hline Question & Group & Wording & Answers \\
\hline 1 & all & $\begin{array}{l}\text { Do you have a background in economics } \\
\text { and/or statistics? }\end{array}$ & yes/no \\
\hline 2 & all & $\begin{array}{l}\text { Where do you expect to see average headline } \\
\text { inflation* in the U.S. over the next two years } \\
\text { after Janet Yellen begins her appointment as } \\
\text { the new chairman of the Federal Reserve } \\
\text { (Fed)? }\end{array}$ & interval \\
\hline 3 & all & $\begin{array}{l}\text { Where do you expect to see average headline } \\
\text { inflation* in the U.S. over the next two years } \\
\text { if Ben Bernanke had remained chairman of } \\
\text { the Fed? }\end{array}$ & interval \\
\hline 4 & 1 & $\begin{array}{l}\text { Were Ben Bernanke to remain Chairman of } \\
\text { the Fed, what would be the probability of } \\
\text { average headline inflation over the next two } \\
\text { years being below } \mathbf{x} \%^{\dagger}\end{array}$ & $\%$ \\
\hline 4 & 2 & $\begin{array}{l}\text { Were Ben Bernanke to remain Chairman of } \\
\text { the Fed, what would be the probability of } \\
\text { average headline inflation over the next two } \\
\text { years being above } \mathbf{x} \%{ }^{\dagger}\end{array}$ & $\%$ \\
\hline 4 & 3 & $\begin{array}{l}\text { After Janet Yellen takes the helm of the Fed, } \\
\text { what is the probability of average headline } \\
\text { inflation over the next two years being below } \\
\mathbf{x} \%^{\dagger}\end{array}$ & $\%$ \\
\hline 4 & 4 & $\begin{array}{l}\text { After Janet Yellen takes the helm of the Fed, } \\
\text { what is the probability of average headline } \\
\text { inflation over the next two years being above } \\
\mathbf{x} \%^{\dagger}\end{array}$ & $\%$ \\
\hline
\end{tabular}

\footnotetext{
${ }^{\dagger} \mathbf{x}$ refers to the mid-point of the interval provided by respondents in questions 2 and 3, respectively. The sign * denoted a footnote in questions 2 and 3 that stated: "* Annual percentage change in the Consumer Price Index (CPI) released by the U.S. Bureau of Labor Statistics".
} 
In total, 184 respondents completed the survey between December 6th 2013 and February 28th 2014. ${ }^{3}$ Table 2 shows descriptive statistics for this sample. Regarding the inflation prediction intervals, we see that they look similar both in terms of spread and mid-point irrespective of whether Janet Yellen or Ben Bernanke is in control. A few respondents factor in some probability for deflation (negative inflation) in their lower bounds, while some indicate at least a possibility for very high inflation (8\%). The mid-points are close to two percent. The mean indicated probability that average inflation is higher or lower than the mid-point is close to 50 percent.

Table 2: Descriptive Statistics

\begin{tabular}{lcccc}
\hline Question & Mean & st.dev. & Min & Max \\
\hline Q1. Economist (0=no, 1=yes) & 1.000 & 0.000 & 1.0 & 1.0 \\
Q2. Yellen lower bound & 1.204 & 0.812 & -2.0 & 4.0 \\
Q2. Yellen upper bound & 2.826 & 1.030 & 1.0 & 8.0 \\
Q2. Yellen mid-point & 2.015 & 0.734 & 0.5 & 5.0 \\
Q3. Bernanke lower bound & 1.157 & 0.753 & -2.0 & 3.0 \\
Q3. Bernanke upper bound & 2.677 & 0.914 & 0.9 & 8.0 \\
Q3. Bernanke mid-point & 1.917 & 0.634 & 0.5 & 5.0 \\
Q4. Prob. smaller/larger than mid-point & 49.497 & 16.966 & 2.5 & 90.0 \\
Observations & 184 & & & \\
\hline
\end{tabular}

Finally, in Table 3, we check whether our randomization strategy worked by comparing answers to questions 2 and 3 among our four groups. Note that randomization only affected question 4 , so there should not be a statistically significant difference in answers to previous questions. Group sizes are similar and close to 50. Lower and upper bounds of the inflation intervals, as well as the mid-points, are similar for the four groups. In column 4 of Table 3, we report P-Values for the Wald test when regressing these outcomes on group indicator variables. The PValues are well above any usually accepted significance level, which suggests that assignment to a group was not related to previous answers. We conclude from these results that our randomization strategy worked.

\footnotetext{
${ }^{3}$ This excludes 2 respondents who indicated that they did not have an economic background and 3 who gave a probability of 0 for inflation below/above their provided mid-points.
} 


\section{Table 3: Randomization}

\begin{tabular}{lccccc}
\hline & \multicolumn{5}{c}{ Mean answer } \\
\cline { 2 - 5 } Question & Group 1 & Group 2 & Group 3 & Group 4 & P > F \\
\hline Q2. Yellen lower bound & 1.272 & 1.183 & 1.051 & 1.318 & 0.426 \\
Q2. Yellen upper bound & 2.972 & 2.937 & 2.636 & 2.745 & 0.354 \\
Q2. Yellen mid-point & 2.122 & 2.060 & 1.843 & 2.032 & 0.311 \\
Q3. Bernanke lower bound & 1.181 & 1.154 & 1.038 & 1.259 & 0.580 \\
Q3. Bernanke upper bound & 2.798 & 2.798 & 2.536 & 2.559 & 0.327 \\
Q3. Bernanke mid-point & 1.990 & 1.976 & 1.787 & 1.909 & 0.407 \\
Observations & 43 & 52 & 45 & 44 & 184 \\
\hline
\end{tabular}

$\dagger$ Column "P > F" reports the P-Value for the Wald test when regressing question answers on group indicator variables. If belonging to a group had explanatory power regarding questions 2 and 3 , this value should be low (e.g. below 0.05).

Figure 1: Surveyed Intervals for Expected Inflation.

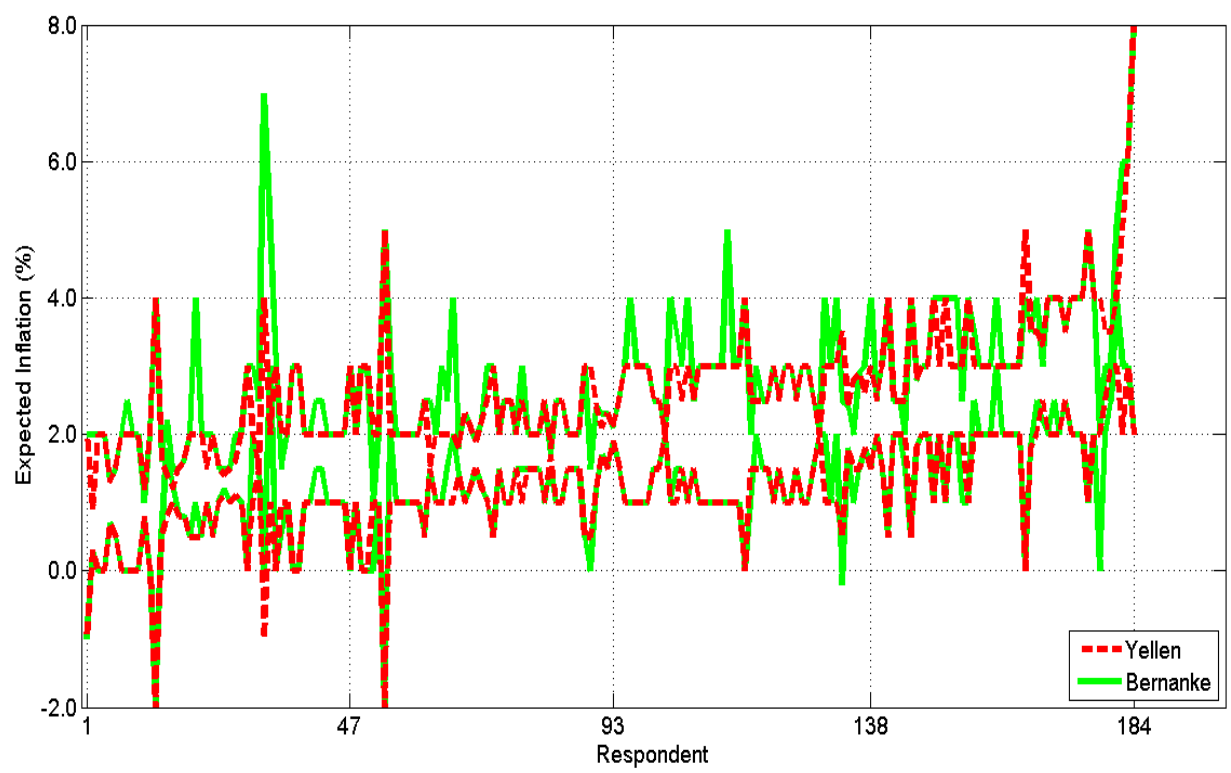

The figure reports surveyed intervals for expected inflation across the respondents and conditional on Janet Yellen (dashed red line) or Ben Bernanke (green solid line) being Fed's chair. The intervals are reordered from the one with the lowest mid-range to the one with the highest mid-range. 


\section{Intervals of Expected Inflation}

As previously illustrated, every survey respondent could specify an interval for expected inflation conditional on Ben Bernanke or Janet Yellen being the Fed chair. Figure 1 reports the provided intervals in an ascending order from the respondent who provided the lowest mid-range.

The majority of respondents gave the same interval for the two scenarios. 57 out of $184(31 \%)$ of them provided a different interval and we compared the samples of lower and upper bounds for the two chairs using the Kolmogorov-Smirnov test to see whether these differences are statistically important. We could not reject the null hypothesis, that the two distributions are the same statistically, with the test statistic of 0.054 (p-value 0.94) for the lower bound and $0.0761(0.64)$ for the upper bound. We plot kernel densities of the four samples in figure 2.

Figure 2: Kernel Densities of Surveyed Intervals.

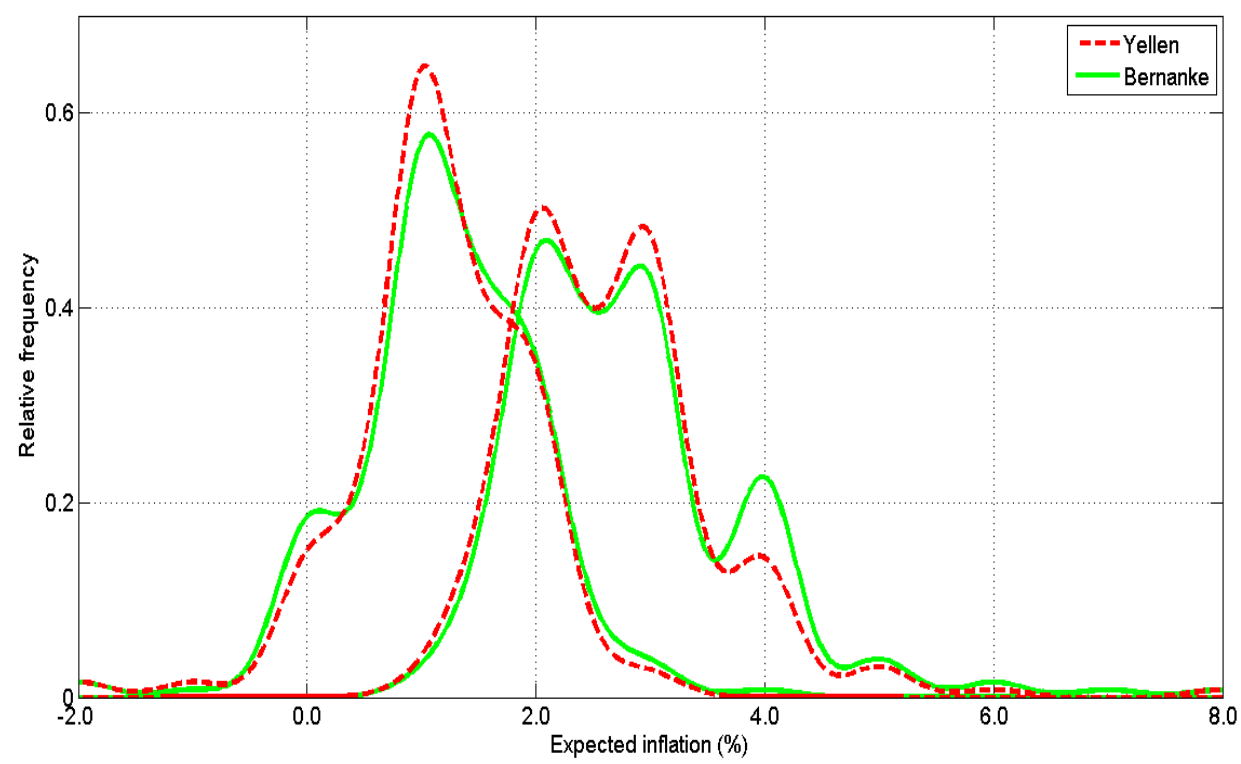

The figure reports estimated densities of lower and upper bound for expected inflation conditional on Janet Yellen (dashed red line) or Ben Bernanke (green solid line) being Fed's chair. The estimate is based on a normal kernel function, using a window parameter (width) that is a function of the given number of points.

Interestingly, if we consider the responses with different intervals for the two scenarios, Janet Yellen was perceived as less, not more dovish than the chairman Bernanke would be. ${ }^{4} 42$ out of 57 mid-ranges of inflation under Yellen are lower

\footnotetext{
${ }^{4}$ Differently from what news agencies in the US were reporting at the time, see for example the
} 
than the corresponding ones under Bernanke, with the average mid-range of 1.957 and 2.273 , respectively. The averages are statistically different with t-stat of 3.16 .

Finally, we compare inflation expectations from our survey to the outcome of the Survey of Professional Forecasters (SPF) released in February 2014. ${ }^{5}$ The most comparable forecasts to our survey consider annual core CPI inflation for 2015 and we plot the mean probabilities from the SPF against mid-ranges under the scenario that Yellen becomes the Fed chair in Figure 3. As it can be noticed, the two distributions are almost equivalent.

This is interesting for two reasons. First, a simple interval survey question leads to the same aggregate expectation distribution at much less of a cost to the individual respondent. Second, our results on symmetry outlined below touch a subject of great interest in the literature, which has mainly focused on the SPF data. As our survey leads to comparable predictions, we think our results connect well to the existing literature.

\section{Figure 3: Comparison to the Survey of Professional Forecasters.}

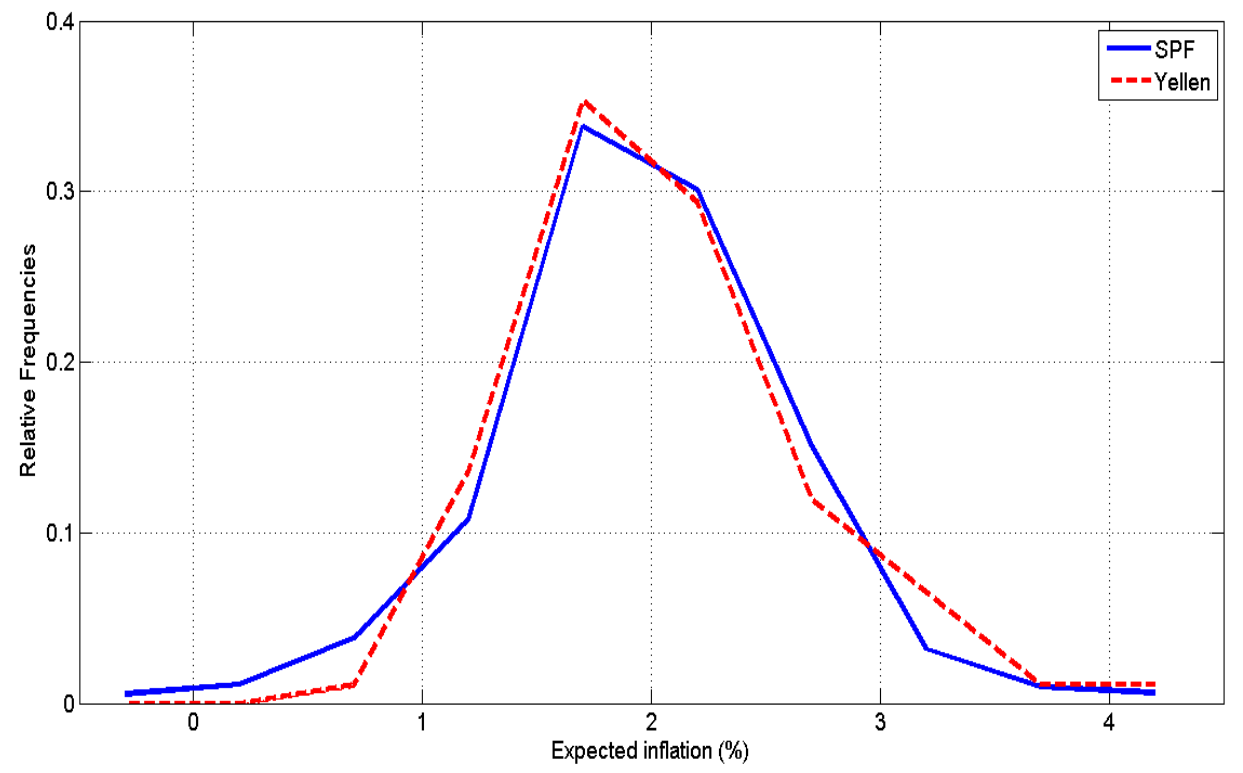

The figure compares mid-ranges for expected inflation conditional on Janet Yellen (dashed red line) being Fed's chair versus annual core CPI inflation forecast for 2015 (solid blue line) from the Survey of Professional Forecasters released in February 2014.

outcome of the "CNBC October Fed Survey" reported by Yahoo! Finance and available here.

${ }^{5} \mathrm{~A}$ complete writeup of the survey is available here. 


\section{Subjective Distributions}

This section illustrates our main result. As already mentioned, we asked the survey respondents in question 4 to provide a probability of expected inflation being higher or lower than a given mid-range. Here, we show that the probability is not statistically different from 0.5 , and thus that subjective distribution functions are on average symmetric.

\subsection{Student's t-test}

To test whether the sample mean has a value of 0.5 , we run Student's t-test on the overall sample, as well as all possible sub-samples resulting from question 4 . We report the results in Table 4 .

Table 4: Student's t-stat

\begin{tabular}{ccccccc}
\hline \hline & \multicolumn{3}{c}{ Below } & \multicolumn{3}{c}{ Above } \\
& No & $\%(\mathbf{x} \%=50)$ & t-stat & No & $\%(\mathbf{x} \%=50)$ & t-stat \\
\hline Bernanke & 43 & 39.5 & -0.37 & 52 & 36.5 & -0.49 \\
Yellen & 45 & 42.2 & -0.74 & 44 & 40.9 & -0.54 \\
\hline Total & 88 & 40.9 & -0.78 & 96 & 38.5 & -0.72 \\
\hline \hline & & \multicolumn{3}{c}{ Total } \\
& & No $\%(\mathbf{x} \%=50)$ & t-stat & \\
\cline { 2 - 5 } & & 95 & 37.9 & -0.61 & \\
& & 89 & 41.6 & -0.91 & \\
& & 184 & 39.7 & -1.07 \\
\end{tabular}

† Column "t-stat" reports the t-statistic for the Student's t-test that the mean of the sub-sample is different from 0.5.

The probability mass on either side of the implicit mean is not statistically different from 0.5 independently of how we split up the sample. We also test whether the average probability from the sub-sample "Below" is statistically different from the "Above" sub-sample using Welch's t-test of equal means. The test statistic is equal to 0.64 (p-value: 0.53 ) and thus we are not able to reject the null hypothesis that two means are statistically the same. 


\subsection{Aggregating Subjective Distributions}

Roughly $40 \%$ of respondents revealed an asymmetric distribution function. In order to assess whether these asymmetries influence the aggregation of inflation expectations, we compare aggregate distributions of mid-ranges $\left(\frac{1}{2} a+\frac{1}{2} b\right)$ with distributions of implicit means, calculated by using the surveyed probability from question 4 and building a two-point probability mass function for each respondent: $\frac{\mathbf{x} \%}{100} a+\left(1-\frac{\mathbf{x} \%}{100}\right) b$. Figure 4 illustrates the idea.

Figure 4: Does Asymmetry Matter for Aggregation?
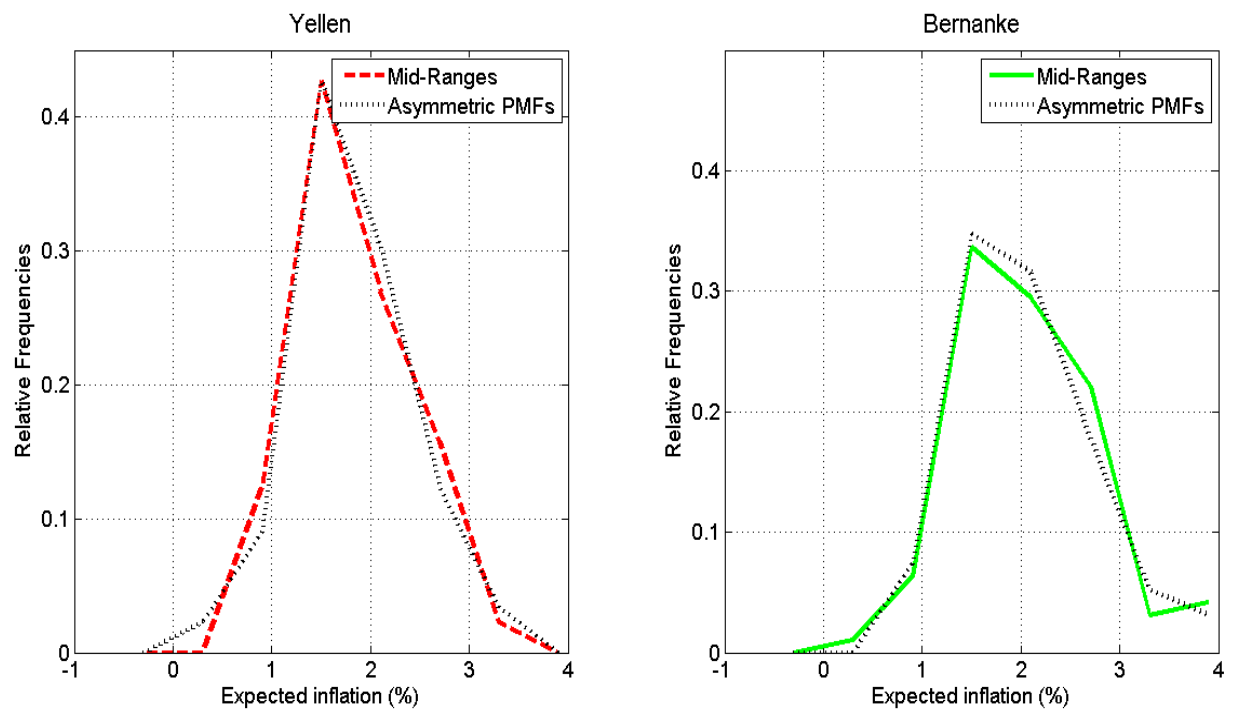

Incorporating skewness of subjective distributions seem to be irrelevant for the aggregate distribution. In other words, subjective distribution functions appear to be symmetric on average. Note that the distribution of mid-ranges conditional on Janet Yellen being Fed's chair is different than the one we reported in figure 3. The reason is that figure 4 regards only those respondents who had to answer question 4 conditional on Janet Yellen being Fed's president (i.e. the groups 3 and 4 , see table 1 ).

\subsection{Robustness Checks}

Our sample consists primarily of non-professional forecasters. If only sophisticated forecasters tend to quantify upside/downside risks by revealing asymmetric distributions, our conclusion that asymmetry does not matter could suffer from a 
selection bias. We address this concern by trying to isolate sophisticated responses in three different ways.

\subsubsection{Interval Length}

We first check whether respondents, who provided narrower intervals and who are arguably less uncertain about their forecast, tend to reveal asymmetric distribution functions. Table 5 shows that almost half of the respondents provided an interval narrower than 1 percentage point (pp), but the surveyed probability is not statistically different from $0.5 .^{6}$

Table 5: The Length of Interval and Skewness

\begin{tabular}{ccccccc}
\hline Range $(\mathrm{pp})$ & No & No $(\mathbf{x} \%=50)$ & $\%(\mathbf{x} \%=50)$ & mean & st.dev. & t-stat \\
\hline less than 1.0 & 88 & 36 & 40.9 & 47.6 & 16.0 & -1.41 \\
$1.0-2.0$ & 64 & 23 & 35.9 & 51.6 & 16.9 & 0.74 \\
$2.0-3.0$ & 22 & 10 & 45.5 & 53.0 & 20.5 & 0.68 \\
more than 3.0 & 10 & 4 & 40.0 & 45.4 & 16.9 & -0.86 \\
\hline
\end{tabular}

$\dagger$ Column "t-stat" reports the t-statistic for the Student's t-test that the mean of the subsample is different from 0.5. The sub-samples are formed according to the surveyed intervals conditional on Bernanke being the Fed's chair and using "Yellen" scenario does not alter the results.

\subsubsection{Fed Chair}

We next look closely at responses that provided different intervals for expected inflation conditional on who would be the Fed's chair. Table 6 shows that the split

\footnotetext{
${ }^{6}$ If we split the sub-sample "1.0 - 2.0" into those who got question 4 with either "Bernanke" (groups $1 \& 2$ ) or "Yellen" (groups $3 \& 4$ ) in it, the average probability is statistically lower than 0.5 for the letter scenario. Nonetheless, the sub-sample is relatively small with only 26 responses. Results available upon request.
} 
does not seem to matter.

Table 6: Bernanke vs. Yellen

\begin{tabular}{ccccccc}
\hline Surveyed Intervals & No & No $(\mathbf{x} \%=50)$ & $\%(\mathbf{x} \%=50)$ & mean & st.dev. & t-stat \\
\hline same & 127 & 57 & 44.9 & 48.6 & 16.3 & -0.93 \\
different & 57 & 16 & 28.1 & 51.4 & 18.3 & 0.57 \\
\hline
\end{tabular}

${ }^{\dagger}$ Column "t-stat" reports the t-statistic for the Student's t-test that the mean of the sub-sample is different from 0.5 .

\subsubsection{CPI or PCE (?!)}

As table 1 illustrates, we asked survey participants to provide expectations for average future CPI inflation. U.S. Fed on the contrary targets inflation as measured by the annual change in the price index for personal consumption expenditures (PCE) ${ }^{7}$ Historically, PCE and not CPI inflation averaged around $2.0 \%$, consistent with the Fed's mandate. Interestingly, surveyed mid-ranges for expected inflation are also close to the Fed's target instead of long-rung CPI inflation as shown in Figure 5 .

Figure 5: Surveyed Distributions vs. History

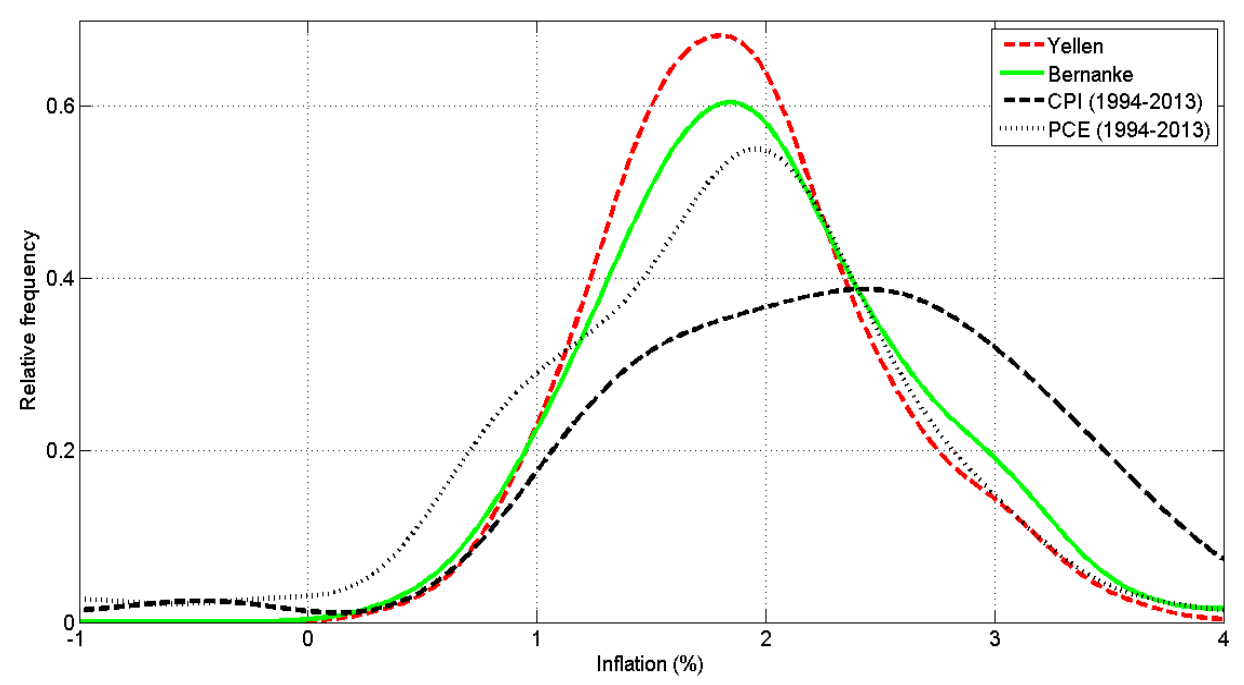

We use this "inattention" to look for responses that provided a mid-interval around the CPI long-term median (2.3\% in the sample from 1994-2013). 32 respondents

\footnotetext{
${ }^{7}$ See the FOMC statement of longer-run goals and policy strategy available here.
} 
provided a mid-interval between 2.1 and $2.5 \%, 13$ out of $32(41 \%)$ gave 0.5 as the probability and the subjective distributions are on average statistically equal to 0.5 (with t-stat of 0.85).

\section{Conclusion}

In this paper we presented evidence from a simple survey that tests for asymmetries in inflation expectation distributions. The survey was conducted among a sample of non-professional forecasters with an economic background. We asked respondents to provide their inflation expectations under two different Fed chairs, Ben Bernanke if he would not have stepped down, and Janet Yellen. Our results do not reveal any patterns of asymmetry in their expectations, implying that the interval mid-points give an accurate representation of average expected inflation, and interval length would be one possible summary statistic for the degree of uncertainty.

These results are in line with several previous studies who analyzed the Survey of Professional Forecasters or similar data sets and found no significant departures from symmetry. However, we caution that our results reflect expectations at a particular point in time, and that it may well be that our findings depend on the general business cycle situation. We address concerns about different degrees in forecasters' sophistication and find no evidence that this aspect matters for symmetry. From a political stand-point, it seems interesting to note that our sampleeconomists from reputable academic and policy institutions-expect lower inflation under Janet Yellen's leadership compared to the hypothetical scenario of Ben Bernanke remaining chair of the Fed.

\section{References}

Alstadheim, Ragna, Ida Wolden Bache, Amund Holmsen, Junior Maih, and Øistein Røisland (2010) "Monetary Policy Analysis in Practice," Norges Bank Monetary Policy Staff Memo, October.

Andersson, Magnus and Boris Hofmann (2009) "Gauging the Effectiveness of 
Quantitative Forward Guidance: Evidence from Three Inflation Targeters," Working Paper Series 1098, European Central Bank.

Bache, Ida Wolden, Øistein Røisland, and Kjersti Næss Torstensen (2011) "Interest Rate Smoothing and "Calvo-Type" Interest Rate Rules: A Comment on Levine, McAdam, and Pearlman (2007)," International Journal of Central Banking, Vol. 7, No. 3, pp. 79-90, September.

Clements, Michael P. (2010) "Explanations of the inconsistencies in survey respondents' forecasts," European Economic Review, Vol. 54, No. 4, pp. 536 - 549.

(2014) "US Inflation Expectations and Heterogeneous Loss Functions, 1968-2010,” Journal of Forecasting, Vol. 33, No. 1, pp. 1-14.

De Bruin, Wändi Bruine, Charles F. Manski, Giorgio Topa, and Wilbert van der Klaauw (2011) "Measuring consumer uncertainty about future inflation," Journal of Applied Econometrics, Vol. 26, No. 3, pp. 454-478.

Engelberg, Joseph, Charles F. Manski, and Jared Williams (2009) "Comparing the Point Predictions and Subjective Probability Distributions of Professional Forecasters," Journal of Business \&amp; Economic Statistics, Vol. 27, No. 1, pp. 30-41.

García, Juan Angel and Andrés Manzanares (2007) "What can probability forecasts tell us about inflation risks?” Working Paper Series 0825, European Central Bank.

Lahiri, Kajal, Christie Teigland, and Mark Zaporowski (1988) "Interest Rates and the Subjective Probability Distribution of Inflation Forecasts," Journal of Money, Credit and Banking, Vol. 20, No. 2, pp. pp. 233-248.

Murasawa, Yasutomo (2013) "Measuring Inflation Expectations Using IntervalCoded Data*," Oxford Bulletin of Economics and Statistics, Vol. 75, No. 4, pp. $602-623$. 